\title{
24
}

\section{BOOTSTRAP - Improving the Capability of Software Industry with Databas Support}

\author{
Janne Järvinen
}

Department of Information Processing Science, University of Oulu, Linnanmaa, FIN-90570 Oulu, Finland. Email: jannej@ rieska.oulu.fi

\begin{abstract}
Software process assessment approaches, methods and methodologies have gained much attention in both MIS and SE areas recently. Perhaps the most well-known approach is CMM (Capability Maturity Model) which was developed by SEI (Software Engineering Institute at Carnegie Mellon University, Pittsburgh). The most well-known European assessment approach is called BOOTSTRAP methodology. The BOOTSTRAP methodology includes both the CMM and the ISO 9000 standards as its starting points. The methodology includes guided assessment process, questionnaires and algorithm for maturity and capability determination, guidelines for process improvement, assessor training program and licensing policy, and computer-based tools and a database that support the consultancy activities.

The database has a unique role in the BOOTSTRAP methodology for providing a basis for the process improvement of software industry. This role is clarified by explaining the development principles, services and architecture of the software tools used in the BOOTSTRAP methodology. Some sample results are presented using the empirical data collected from over 100 software process assessments made in Europe during 1991-1993 under auspices of the ESPRIT/ Bootstrap project.
\end{abstract}

\section{Keyword Codes: D.2.0; 1.6.0; K.6.3}

Keywords: Software Engineering, General; Simulation and Modeling, General; Management of Computing and Information Systems, Software Management

\section{INTRODUCTION}

Process assessment and improvement methodologies came into the highlight of discussion throughout the software industry since the Software Engineering Institute published its maturity model for software process capability determination in 1987 [4]. This model has further been developed into the CMM framework [9]. During the last three years an ESPRIT project BOOTSTRAP developed a European process assessment and improvement methodology, where the original SEI model was applied as one of the main background approaches. BOOTSTRAP Project assessed also the capability of the European software industry using the methodology developed within the project. [8] 
Shortcomings of the SEI model (see for example [2]) and the lack of European and ISO 9000 (see for example [3]) perspective motivated the development of the BOOTSTRAP software process assessment and improvement methodology. BOOTSTRAP extended the SEI approach and adjusted it to suit European software production. This was done mainly by expanding the target group, adapting the ISO 9000 quality standards and adding state-of-theart software engineering ideas to the methodology.

Firstly, the Bootstrap software process assessment methodology is introduced. Secondly, the role of the database and software tools used by Bootstrap are reviewed. Then a sample of empirical Bootstrap assessment data is presented with a specific interest in presenting the role and meaning of the BOOTSTRAP database for European software industry. Finally, the pros and cons of the database support are considered.

\section{BOOTSTRAP METHODOLOGY}

The BOOTSTRAP methodology was developed during an ESPRIT technology transfer project whose purpose was to fertilize the soil for the introduction of modern and adequate software technology into European software and software intensive industry. The European assessment methodology was needed because it was felt that the SEI approach was aimed mainly for very large embedded defence systems that did not face the European software production problems.

When developing the methodology BOOTSTRAP Project adopted and extended the original SEI approach with features that were found necessary in the European context, and to attain more detailed diagnosis of the capability of the organizations and their projects ([1]). The aim was to define an improvement path for software producing units with distinct milestones. The software process maturity framework by Humphrey [5] provided a basis for the milestones and ISO 9001 [6] and ISO 9000-3 [7] were used as a framework for the quality system of the BOOTSTRAP methodology in general.

A specific goal of the BOOTSTRAP methodology is to reduce risks related to software production. Management is the key factor to achieve this goal implying that the development should start with development of the organization. In the well-functioning organization the development of the methodology can then commence. When the methodologies are adopted in the organization it is then ready to adopt also the technologies that will support the methodologies in use. It is also important to understand that the technologies are marginal in respect to the growth of productivity and quality - the elements needed to reduce risk.

The BOOTSTRAP methodology includes description of guided assessment process, maturity and capability determination instruments (questionnaires and algorithm), guidelines for process improvement (standards for action plan generation), and assessor training program. The methodology is supported with computer-based tools and a continuously updated European database that provides an excellent opportunity to compare the maturity and capability levels of the company assessed for example with the rolling means of similar companies in Europe. 


\subsection{The Role of Database in Bootstrap Assessments}

The development of the BOOTSTRAP database had two main goals; to assist the Bootstrap assessments and to help in improving the capability of the European software industry.

An important starting point for achieving these goals was the ability to map the state-ofpractice of software engineering in Europe. Therefore, as assessments have been conducted, the results have been collected to a database. At present this database is situated in Oulu, Finland and it is maintained by the Finnish Bootstrap partners, the CCC companies and the University of Oulu.

During a BOOTSTRAP assessment when the data is collected it is then transferred into the database and compared with rolling means of similar companies or projects. Therefore, using the Bootstrap database it is possible to view the different average maturity profiles of different segments or countries and compare a new organization to these profiles. This gives a good indication on the status of the organization in relation with others among the chosen segment.

The primary goal of an individual Bootstrap assessment is to measure and develop an SPU quality profile analytically, discovering strengths and weaknesses of the assessed SPU. Secondly the assessment will derive the steps for improvement from the strengths-andweaknesses profile (see figure 1) in terms of a plan of recommended actions to be taken immediately. The average profiles from the Bootstrap database may be used in creating this profile. The third object of the assessment is to transform the action plan into a series of 'miniprojects' (see table 1) for implementing the recommended improvement steps.

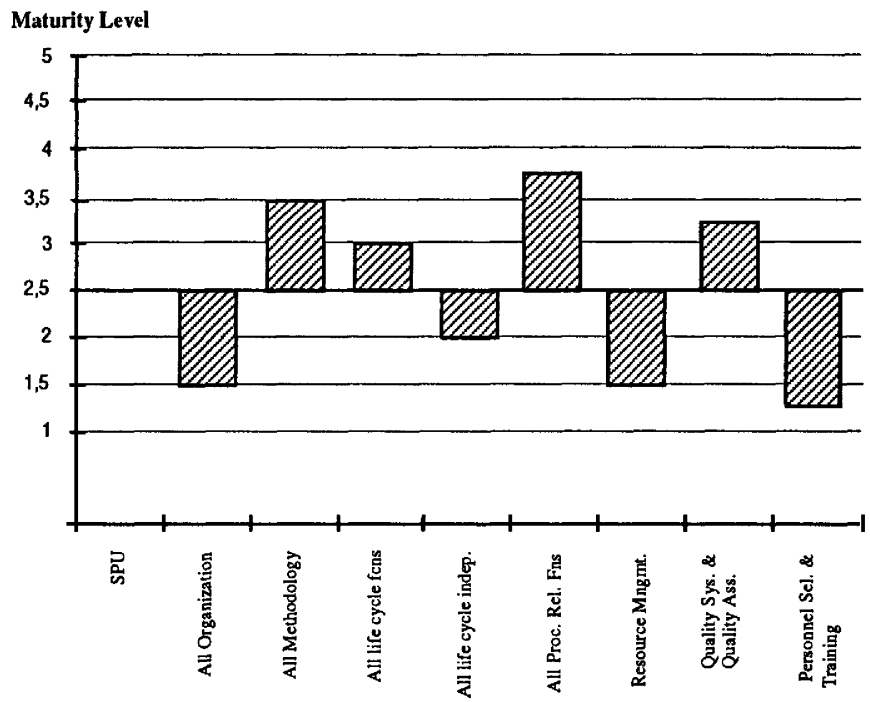

Figure 1. Example of an SPU strengths and weaknesses profile. 


\section{THE BOOTSTRAP DATABASE SOLUTION AND SOFTWARE TOOL SUPPORT}

BOOTSTRAP tools are computer-based facilities that automate parts of the data collection, counting, data analysis, result presentation and data retrieving from the BOOTSTRAP database. The BOOTSTRAP database is a central database that includes all the data captured during the assessments performed by the licensed BOOTSTRAP assessors.

The architecture of Bootstrap Tools and Database is based on a client-server solution (cf. figure 2.). Bootstrap tools are used in client PCs and the complete, central database is located in a unix-based server computer at the Bootstrap Center. Additionally, licencees may have local databases that contain their own assessment data.

Table 1. Example of an SPU action plan table.

\begin{tabular}{lllllll}
\hline Action & Effort & $\begin{array}{l}\text { Precon- } \\
\text { ditions }\end{array}$ & $\begin{array}{l}\text { Qualifi- } \\
\text { cation } \\
\text { needed }\end{array}$ & $\begin{array}{l}\text { Priority } 1 \\
\text { (impor- } \\
\text { tance) }\end{array}$ & $\begin{array}{l}\text { Priority } \\
2 \\
\text { (success) }\end{array}$ & $\begin{array}{l}\text { Final } \\
\text { priority }\end{array}$ \\
\hline $\begin{array}{l}\text { Testing } \\
\text { education }\end{array}$ & $\begin{array}{l}3 \text { person } \\
\text { months, } 10 \\
\text { tmk }\end{array}$ & Seminar & $\begin{array}{l}\text { SW } \\
\text { Technology }\end{array}$ & 3 & 4 & 3 \\
$\begin{array}{l}\text { Develop- } \\
\text { ment }\end{array}$ & $\begin{array}{l}6 \mathrm{pm} \\
\text { handbook }\end{array}$ & $\begin{array}{l}\text { Documents } \\
\text { available }\end{array}$ & $\begin{array}{l}\text { Senior SW } \\
\text { Engineer }\end{array}$ & 2 & 1 & 1 \\
$\begin{array}{l}\text { Purchase } \\
\text { evaluation } \\
\text { method }\end{array}$ & $\begin{array}{l}2 \mathrm{pm}, \\
40 \mathrm{tmk}\end{array}$ & Tool study & $\begin{array}{l}\text { Junior SW } \\
\text { Engineer }\end{array}$ & 5 & 5 & 5 \\
\hline
\end{tabular}

\subsection{BootBase - The Bootstrap Database}

The Bootstrap database is called BootBase. It is a database that includes all data collected in the BOOTSTRAP assessments since autumn 1990.

BootBase provides a valuable resource for the European software industry for at least the following reasons:

- The database can be used to generate mean profiles of European and national status of software engineering and especially report the state-of-practice within a specific domain of interest, ie. banking, telecommunications etc.

A client organization can use the mean profiles to compare themselves to other companies in the field and obtain information on how to focus their improvement efforts.

- BootBase can serve as an aid for generating improvement action plans for an organization as similar organizations may be traced from the database without breaching confidentiality.

- The database will serve as a source of information for comparing the status of software production in Europe to software production in USA and Japan. 


\subsection{Bootstrap Tools}

The Bootstrap tools offer assistance for assessors during the assessment process and enable the data gathering and analyzing functions. These tools are introduced here briefly.

The BootCollector is used for collecting assessment information and supporting the assessors work during an assessment session. The assessment information is then transferred further into the data base and for results processing.

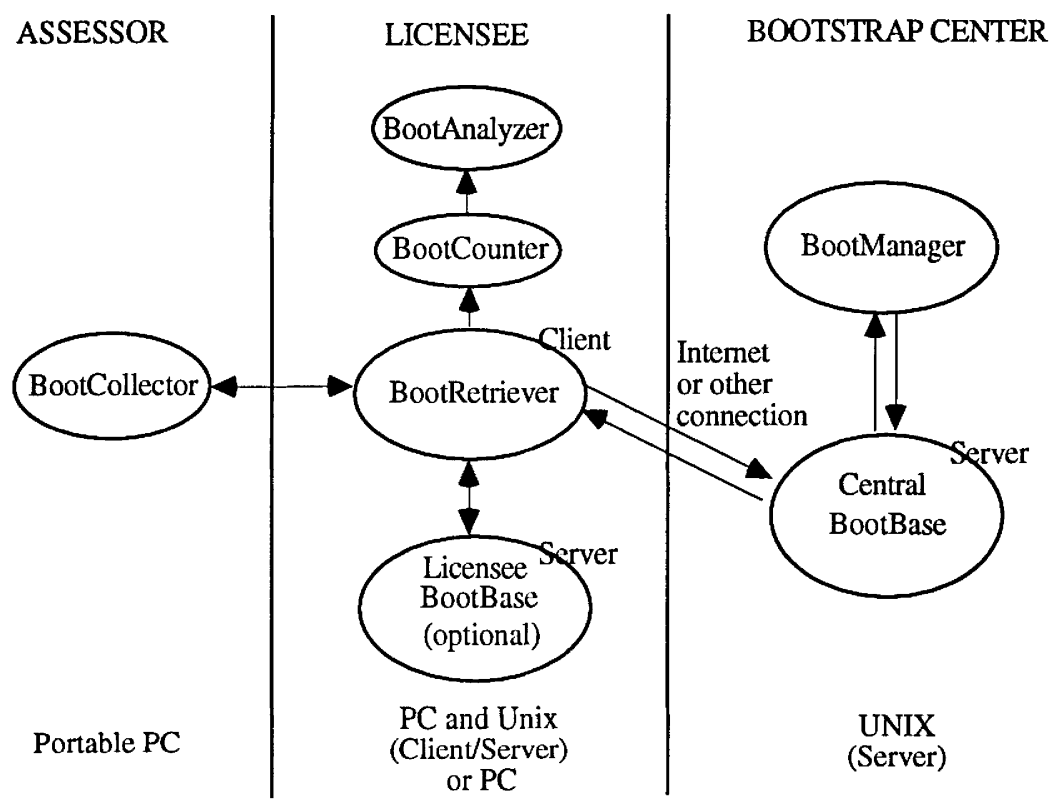

Figure 2. The overall architecture of the Bootstrap Tools and Database.

The BootRetriever, BootCounter and BootAnalyzer form a software package for calculating and displaying the assessment results both in graphical and textual form. The BootManager is a software package for BootBase management and operation in the Bootstrap Center.

The BootRetriever can also be used for performing queries into the Bootstrap database and also as an interface tool between assessors and the Bootstrap Center.

BootAnalyzer also supports assessors in the generation of action plans. The assessment results give detailed description of the strengths and weaknesses of the assessed unit (cf. figure 1). These attributes can be used when designing or verifying the improvement actions. With BootAnalyzer it is also easy to compare possible scenarios of future situations.

Using the Bootstrap database and software tools it is possible to view the different average maturity profiles of different segments or countries and compare a new organization to these 
profiles. This will give a good indication on the status of the organization in relation with others among the chosen segment.

\section{SAMPLE RESULTS FROM BOOTSTRAP ASSESSMENTS}

The sample results of the assessments performed during the BOOTSTRAP project contain overall maturity levels of the SPUs and projects and mean values of the key attributes forming capability profiles of the SPUs and projects. Here only the maturity level results will be presented, because the mean values of capability profiles have been kept confidential and counted in different ways for different purposes.

The maturity levels that are presented in the following two figures (Figure 3 and 4) have been counted based on the assessed 37 SPUs and 90 projects during the first and second phases of the BOOTSTRAP project. The figure 3 presents percentage distribution of SPUs on different maturity level quartiles and the figure 4 the same for the projects.

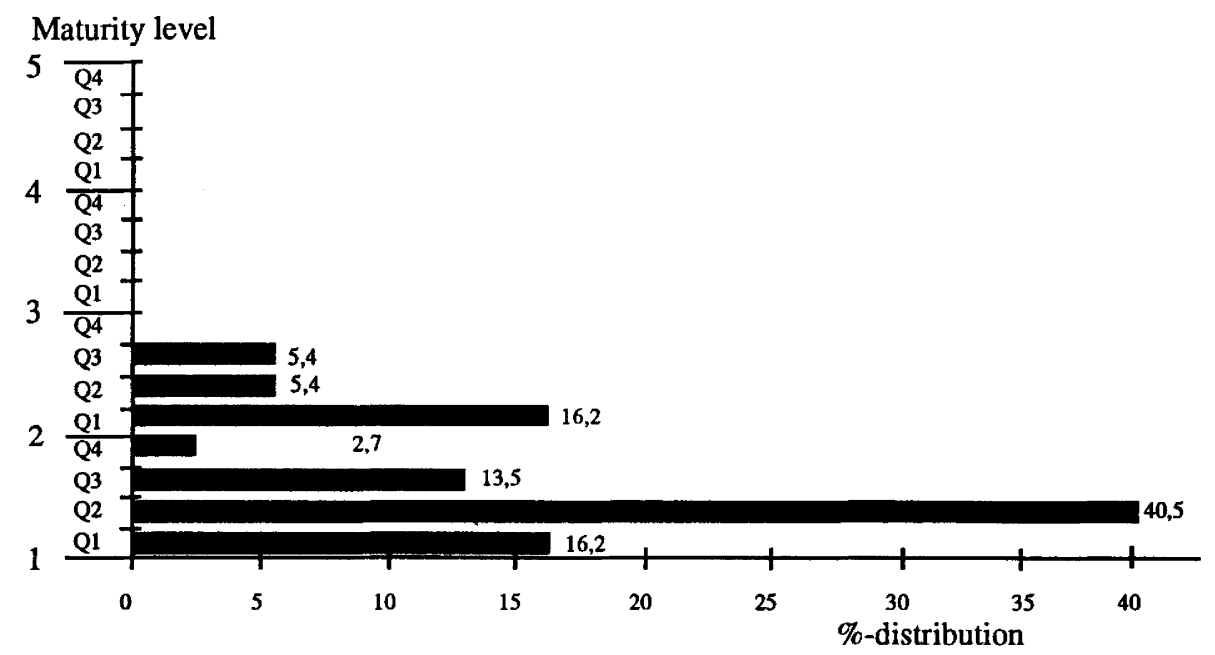

Figure 3.Sample of maturity levels of SPUs in Europe (37 SPUs)

The size of the sample results of the Bootstrap assessments is too small to draw firm conclusions based on it concerning European state of the practice in software production. The only remark that can be made is that the maturity level of the projects seem to be marginally better than with the SPUs. This is the fact when compared the maturity of the SPU with its projects, although the average level computation over the samples above show a slightly opposite result. The tentative explanation for the remark could be that new practice and technology have been adopted first in the projects after that it is perhaps transferred into standard use in 
the SPU. The result motivates also to use separate questionnaires on the organization and project levels in the way that is included in the BOOTSTRAP methodology.

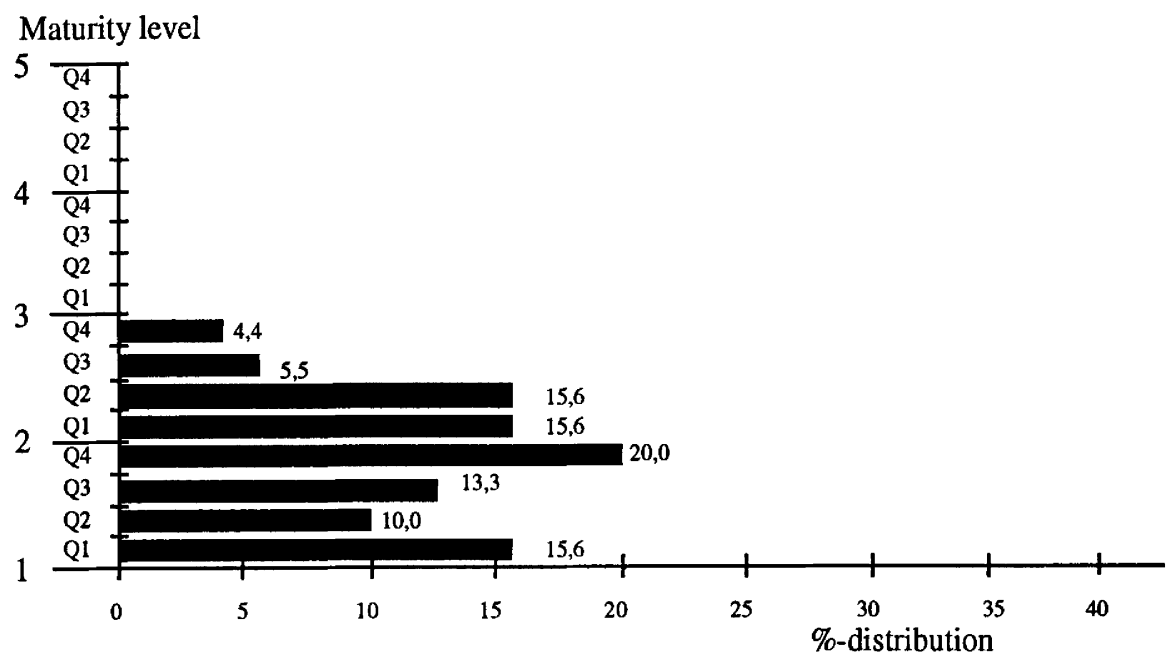

Figure 4. Sample of maturity levels of software projects in Europe (90 projects)

\section{DISCUSSION}

A well designed and maintained database can be a valuable asset in an attempt to take a broad perspective on the improvement of the software industry. The Bootstrap database contains very current data as the database is continuously being updated with new assessment data from the Bootstrap Licencees. The data should also be quite consistent and comparable because Bootstrap assessments are controlled and can only be performed by assessors who have received proper training.

The Bootstrap database support facilitates the recording and analyzing of the assessment results and helps in designing plans for improvement. For the software industry and its various segments the database provides detailed state-of-practice data that can be used in evaluating the capability and potential of the industry. An individual organization can benefit greatly from the experiences of other similar organizations and also track its progress with the help of the database.

The Bootstrap database can also serve a more general use for the software industry. The database can provide valuable information for the planning of improvement directions for the industry about the areas where improvement is most needed. Also in the process of organizational knowledge creation [10] and in particular inter-organizational knowledge 
creation and utilization the Bootstrap database can be of help in focusing the resources allocated to the development of the software industry.

As with any other software process assessment methodology, Bootstrap is not a finished product but an evolving one. Many questions remain to be answered. For example, how can we be sure that our method with the database support yields assessment results that represent the reality in an organization? Or what is the true meaning of increased maturity and capability?

\section{CONCLUSION}

It is difficult to assess software processes and compare the assessment results of software producing units and their processes. Although a general framework is beneficial for the software industry there remains much work in uncovering the specific properties of the different types of software producers. An organization which does telecommunications software is very different from an accounting software company; a real-time process control software company has other requirements for its organization and processes than an in-house MIS unit. With the help of Bootstrap data and feedback from the industry we hope that we are able to identify some of the properties of these different domains and thus participate in the inter-organizational learning process and work of improving the capability and of software industry in general.

\section{REFERENCES}

1. Bicego, A., Cachia, R., Haase, V., Koch, G., Krzanik, L., Kuvaja, P., Lancelotti, R., Maiocchi, M., Messnarz, R., Saukkonen, S. Schynoll, W. and Similä, J. 'Bootstrap: Europe's Assessment Method.' IEEE Software, pp. 93-95, May, 1993.

2. Bollinger, T. B. and McGowan, C. 'A Critical Look at Software Capability Evaluations', IEEE Software, pp. 25 - 41, July, 1991.

3. Bamford, R. C. and Deibler W. J, Comparing, contrasting ISO9001 and the SEI capability maturity model, COMPUTER, October, 1993.

4. Humphrey, W. S. Characterizing the Software Process: A Maturity Framework. Software Engineering Institute, CMU/SEI-87-TR-11, DTIC Number ADA182895, June, 1987.

5. Humphrey, W. S. Managing the Software Process, Addison-Wesley, Reading, Mass., 1989.

6. ISO 9001, Quality Systems; Model for Quality Assurance in DesignDevelopment, Production, Installation and Servicing, 1987.

7. ISO 9000-3, Quality Management and Quality Assurance Standards, Part 3: Guidelines of ISO 9001 to the Development, Supply and Maintenance of SW, 1991.

8. Kuvaja, P., Bicego, A. 'Bootstrap: a European Assessment Methodology', to be published in Software Quality Journal, June 1994.

9. Paulk, M. C. et al, Capability Maturity Model for Software, Version 1.1, Software Engineering Institute, Technical Report CMU/SEI-93-TR24, 1993.

10. Nonaka, Ikujiro, A Dynamic Theory of Organizational Knowledge Creation, Organization Science, Vol. 5 , No. 1, February 1994. 